\title{
Utopias/distopias e heterotopias em dispositivos de design: reflexão metaprojetual sobre Casas Colaborativas
}

\section{Utopias/dystopias and heterotopias in design dispositifs: metadesign reflection on Collaborative Houses}

\author{
Claudia Palma da Silva, Unisinos. \\ claudiapalmadasilva@gmail.com \\ Ione Maria Ghislene Bentz, Unisinos. \\ ioneb@unisinos.br
}

Carlo Franzato, Unisinos.

cfranzato@unisinos.br

\begin{abstract}
Resumo
Este artigo propõe uma abordagem metodológica aplicável aos estudos de design que se apropriam de espaços compreendidos como heterotópicos. Para isso, o potencial dos conceitos de utopia/distopia é explorado nos processos de design estratégico para a inovação sociocultural e sustentabilidade. A reflexão, de caráter metaprojetual, é orientada pelas formulações estratégicas que Foucault desenvolve, ao desdobrar o conceito de dispositivo. Concentra-se, especialmente, sobre as iniciativas denominadas Casas Colaborativas que, nessa década, emergiram às margens dos ecossistemas culturais brasileiros, logo ganhando relevância. As práticas heterotópicas, orientadas pelas utopias/distopias, são elaboradas pelos coletivos criativos que convivem nessas casas, e representam descontinuidades nos modos de pensar e agir em espaços urbanos. Daí resultam dispositivos de design oriundos de processos de imaginação, criação e projetação, alternativos aos dominantes, e pautados por outras concepções de bem-estar.
\end{abstract}

Palavras-chave: Utopias, Heterotopias, Distopias, Dispositivos, Casas Colaborativas, Inovação Sociocultural, Metaprojeto

\begin{abstract}
This article proposes a methodological approach useful in the design studies that considers heterotopic spaces. For this purpose, the potential of the concepts of utopia/dystopia will be explored in the processes of strategic design for sociocultural innovation and sustainability. This metadesign reflection is oriented by the strategic formulations that Foucault develops when facing the concept of dispositif. It focuses especially on the initiative called Collaborative Houses that emerged in this decade, on the margins of Brazilian cultural ecosystems, and soon gained relevance. The creative collectives that live in these houses elaborate heterotopian practices that are driven by utopias/dystopias and represent discontinuities in the ways of thinking and acting in the urban spaces. As a result, design dispositifs emerge from these processes of imagining, creating, and designing. Oriented by driven by other conceptions of well-being, these dispositifs are alternative to the dominant ones.
\end{abstract}

Keywords: Utopias, Heterotopias, Dystopias, Dispositifs, Collaborative Houses, Sociocultural Innovation, Metadesign 


\section{Introdução}

Assistimos, na atualidade, à falência de algumas utopias que embalaram os sonhos de prosperidade e bem-estar da humanidade, no último século. Por exemplo, a utopia tecnológica traria igualdade de oportunidades, qualificação do trabalho e espaço para o lazer. A utopia da globalização dissiparia as fronteiras físicas, aproximaria os povos e as culturas e favoreceria os mercados e a distribuição da riqueza. Se a realidade não corresponde a essas expectativas, é verdade que os ideais se mantêm vivos em busca de novas formas de viabilizá-los. Assim, projetar torna-se cada vez mais necessário. No design contemporâneo, o conceito de inovação destaca-se sobremaneira, vinculado que está com a promoção do desenvolvimento humano. Nesse sentido, poderia ser produtivo contrapor às utopias as distopias subversivas (ARGAN, 2004; DI SALVO, 2012), não como processos adversários na idealização de um lugar hegemônico, mas como parceiros na construção de alternativas para as transformações desejadas? Já não estariam em curso iniciativas que contribuem para mudanças socialmente relevantes?

Colaboração e sustentabilidade são invocados nesses desafios. Se o espaço de liberdade para formular e discutir é conditio sine qua non para o florescimento de ideias e para a ocorrência de debates, a colaboração e o empreendedorismo correspondem, respectivamente, a uma atitude de 'fazer junto', de trocar referências e de expressar desejos que, em sinergia, constituem o fazer criativo de construção de uma realidade sustentável. Considerado como estratégia de ação, o design contemporâneo, entre outras tantas estratégias, encontra, na colaboração e no empreendedorismo, espaço para trabalhar em prol desse desejado tipo de transformação. Essa atuação é expressão da vontade coletiva e é motivada por questões mais abrangentes que afligem significativas camadas da sociedade. Nada idiossincráticas, essas necessidades estimulam processos criativos e impulsionam o design em ações comprometidas e transformadoras.

Tais premissas estão presentes nas práticas das Casas Colaborativas, razão pela qual são objeto desta reflexão. Elas são organizações recentes que emergiram e floresceram no Brasil na última década, especialmente, nas grandes capitais. Trata-se de espaços compartilhados por jovens criativos e empreendedores, de diversas áreas de atuação, entre elas, o design, que se juntam para dividir os custos e para colaborar em projetos coletivos, normalmente voltados a propósitos maiores, como a inovação social, a sustentabilidade e a elaboração de propostas culturais.

Para compreensão dos parâmetros que orientam as práticas das Casas Colaborativas, chamase o concurso da metodologia do design estratégico, em abordagem metaprojetual, compreendida não apenas pelo deslocamento entre os níveis de projeto e metaprojeto, mas na confluência de deslocamentos em termos de níveis de conhecimento. Considera-se o metaprojeto pela visão de deslocamentos entre os diversos níveis de conhecimento, combinados com o próprio deslocamento que ocorre nas instâncias estritamente projetuais. Tal proposição é 
apresentada por Bentz e Franzato (2016), que compreendem metaprojeto como um processo de deslocamento que opera também nos níveis de conhecimento de diferentes grandezas, e que requerem configuração distintiva. Assim, os processos de design que se materializam em projetos correspondem ao nível de identificação dos objetos de análise. Esse se torna suporte para o nível de investigação metaprojetual, que se define pelo nível metodológico - neste caso, o design estratégico, que, por sua vez, responde a um dado paradigma de conhecimento. Tais níveis estão em permanente interação, definindo-se um ao outro recursivamente.

\section{Design Estratégico}

O processo metaprojetual enquadra-se na compreensão do design estratégico que tem em Mauri (1996), Manzini (2008) e (Zurlo (2010) sua principal inspiração. Zurlo (2010) orienta atividades de projeto para a definição de estratégias de tomada de decisão nas organizações, de que resultam respostas para o encaminhamento de soluções para problemas em nível de sociedade, de mercado ou de meio ambiente. Em consequência, o projeto trabalha desde a criação à implantação de estratégias que são percebidas como criação de efeitos de sentidos, em especial, de valor simbólico, dos quais resulte a percepção de valor agregado em artefatos de design. Os direcionamentos para a prática do design como atividade de colaboração e empreendedorismo, centrais neste trabalho, são diretamente dependentes da presença dessas competências no fazer projetual. Assim, essa tríade corresponde a perceber, interpretar, imaginar, traduzir, expressar e difundir, ou seja, a operar com processos de significação em busca de novos sentidos, em especial, antecipatórios de futuros, ou especulativos em relação ao presente.

O potencial da metodologia do design estratégico está relacionado: (i) à abertura que propõe para agregar a contribuição de diferentes disciplinas; (ii) a uma compreensão de sistema que une produtos-serviços-comunicação (sistema produto-serviço - SPS); (iii) à inclusão das incertezas como desafios capazes de fomentar o uso da criatividade e da imaginação; e (iv) à inventividade com que trabalha seus processos e desenha situações favoráveis a seus objetivos sociais humanísticos. Como consequência, competências como criatividade e imaginação são agregadas à cultura de projeto.

Manzini (2008) destaca a relevância da inovação social que orienta, pelo design estratégico, o modo como os indivíduos ou comunidades agem para resolver problemas, ou para identificar oportunidades em escala local. Para o autor, essas inovações são guiadas antes pela mudança de comportamento do que por outros tipos de mudanças, sejam tecnológicas ou mercadológicas, que levem a sociedade a elaborar novas concepções de bem-estar. Também para Meroni (2008), o design é regido pela mudança comportamental e pela obtenção de resultados, além de envolver a resolução de problemas e, ainda, a geração de oportunidades. Vão nessa mesma direção as formulações metodológicas de Franzato et al. (2015), que recorrem ao conceito foucaultiano de dispositivo para trabalhar a dimensão estratégica da ação projetual e, 
consequentemente, destacam a relevância do design para a elaboração cultural, assim afirmando o conceito de inovação cultural e social.

Alinham-se a essas formulações os estudos sobre inovação social de Mulgan et al. (2007) e Murray, Caulier-Grice e Mulgan (2010), preocupados, respectivamente, com o compromisso das organizações e com os negócios e empreendimentos. Apresentam uma crítica ao status quo socioeconômico vigente e pontuam a necessidade de promover deslocamentos nas propostas de empreendedorismo, no sentido de fundamentar projetos de desenvolvimento social no pilar dos valores humanistas. Nesse sentido, as dinâmicas que pautam as mudanças na sociedade estão sempre em mutação, seja de modo mais lento ou gradual, e são elas que exigem, daqueles projetos comprometidos com o desenvolvimento sustentável da sociedade, a renovação dos processos projetuais criativos e a proposição de artefatos catalisadores da transformação desejada.

Na próxima seção, tais elaborações conceituais sobre inovação sociocultural serão inscritas no âmbito das teorias propostas por Foucault sobre estratégias e dispositivos, utopia e heterotopias.

\section{Dispositivos e Utopias}

Colaboração e empreendedorismo são práticas estimuladas ou favorecidas pelos dispositivos. Se retomarmos a compreensão de que o design trabalha ecossistemas por processos projetuais criativos para criação de dispositivos que transformem o mundo (FRANZATO et al., 2015), esses dispositivos assumem um papel relevante na produção da inovação sociocultural.

No que diz respeito a dispositivos, Foucault (1970) tem influenciado os estudos sobre esse tema. Ele diz corresponder a um conjunto heterogêneo que é constituído por discursos, instituições, práticas, mecanismos, leis, medidas e regras, tanto quanto enunciados científicos e filosóficos ou práticas de diferentes ordens, tecidos em redes de relações de poder. Tais tessituras produzem-se em elementos manifestos ou subjacentes, com potencial para orientar ou controlar, mas também para fomentar ou transformar. Apropriados pelo design, os dispositivos são parte integrante dos processos projetuais.

Foucault (1970) destaca os dispositivos pelas atuações nas relações de poder ${ }^{1}$. Essa associação é particularmente relevante para o design nas suas relações estéticas e políticas, dada a realidade contemporânea, controversa no choque entre as garantias civilizatórias conquistadas e o obscurantismo de forças reacionárias saudosas de um passado perdido, feito do poder estável outorgado por poder econômico, etnia ou nobreza. Os estudos foucaulteanos identificaram a presença explícita de mecanismos de poder derivados dos objetos culturais produzidos pelo

\footnotetext{
${ }^{1}$ Para Foucault (1970), não existe apenas poder, mas relações de poder que através de seus mecanismos atuam como forças, coagindo, disciplinando e controlando os indivíduos.
} 
homem e que acabam por subjugá-lo. Por vezes, transparentes à sociedade, seus efeitos nem sempre são percebidos.

O design, pela sua vocação transformadora e criativa, seria o locus preferencial para oferta à sociedade de artefatos que possibilitassem a transformação do mundo na direção dos sonhos legítimos de uma sociedade de prosperidade e bem-estar, mas, também, de sustentabilidade. Tais artefatos poderiam favorecer, portanto, a materialização desses sonhos se pautados pela ética da responsabilidade com o outro, com o mundo e consigo. Extensivos às organizações, esses ideais encontram espaço para inovações significativas em empresas, escolas, prisões ou fábricas, por exemplo, e na reformulação crítica de códigos de lei, de normas de comércio e de dispositivos legais de toda ordem. São poderosos auxiliares no desenho do futuro.

Nas Casas Colaborativas, esses dispositivos são de diferentes naturezas e inspirações (o que se verá nas experiências das Casas a seguir compartilhadas), mas todos atuam na preservação ou na inovação das práticas e processos e, portanto, na produção de resultados. Dos dispositivos às utopias, há conexões, uma vez que os dispositivos afetam a produção de utopias/distopias em heterotopias, e são também por elas afetados.

A compreensão de que as transformações sociais possam ser construídas na inflexão entre real e imaginário, são estímulos à criatividade. Entende-se utopia como espaço de sonho e de imaginação, por excelência, verdadeira força motriz para inovação em termos de conceitos e valores. Assim sendo, a ideia de vanguarda e de utopia estão intimamente ligadas e, para o design, se apresentam como instâncias estratégicas. Como diz Foucault (1991), as utopias confortam, senão dispõem do tempo real e disseminam-se em um espaço maravilhoso.

Ao examinar os tipos de posicionamentos chamados de espaço por Foucault (2004), ele os classifica como utopias e heterotopias. As utopias "são posicionamentos sem lugar real" (ibidem, p. 45) que mantêm analogia com aqueles percebidos na sociedade, mas que são irreais. Entretanto, essa mesma sociedade cria, no interior da sua cultura, organizações cujos dispositivos são de natureza contestatória e irreverente, verdadeiras construções de contracultura. Desse processo, resultam lugares reais que, contudo, não correspondem aos parâmetros de aceitação estabelecidos pelas normas vigentes. São heterotopias. Esses espaços heterotópicos são lugares de conflitos e de tensões dos quais resultam mudanças expressivas, sempre novas, pois fogem às regras vigentes e rompem o status quo. Nesse sentido, os espaços projetuais assim caracterizados trazem expectativas de diferenciação em relação às práticas usuais da sociedade, donde seu caráter promissor. Para Foucault (1991), a heterotopia causaria efeitos que vão além da ordem pública, pois esse tipo de espaço causa uma sensação de desconforto em todos aqueles que dele fazem parte, pelo seu caráter crítico e transformador.

Heterotopias são sempre topos materiais ou imateriais, sem fronteiras físicas ou geográficas, topos de natureza espaço-temporal, topos definidos por ações transversais na busca da utopia. Enquanto a utopia é sempre uma força tensionadora, e não um espaco-tempo a ser alcançado de fato, as heterotopias são vivenciadas hic et nunc e é onde se processam as transformações. Isso 
equivaleria a dizer que parte relevante da pesquisa em design deveria ocupar-se da proposição de novos dispositivos comprometidos para além dos fins ético-estéticos e políticos específicos da ação projetual.

Além disso, projetos em espaços heterotópicos resultariam em dispositivos que favoreceriam o desenvolvimento de distopias ecossistêmicas, isso porque é nas distopias que se observam narrativas predominantes, ou seja, que se sobrepõem umas às outras, em uma tensão de forças de poder, pois as utopias são os espaços das narrativas hegemônicas. No lugar de contrapor utopia versus distopia, propõe-se aqui associar utopia e distopia. A utopia, então, faz sonhar, e a distopia marca os desvios, contradições e diferenças, ou seja, representa, de fato, a possibilidade de inovação.

Na linha da organização ecossistêmica que se propõe para Casas Colaborativas, as distopias, teriam sua expressão na utopia, em que vários relatos existiriam como possíveis e harmonizados em uma narrativa maior, capaz de subsumir os potenciais significados por uma linha isotópica, no sentido greimaseano (GREIMAS, 1973). Então, a isotopia poderia ser o princípio ordenador dessas múltiplas organizações, como mostra a figura 1.

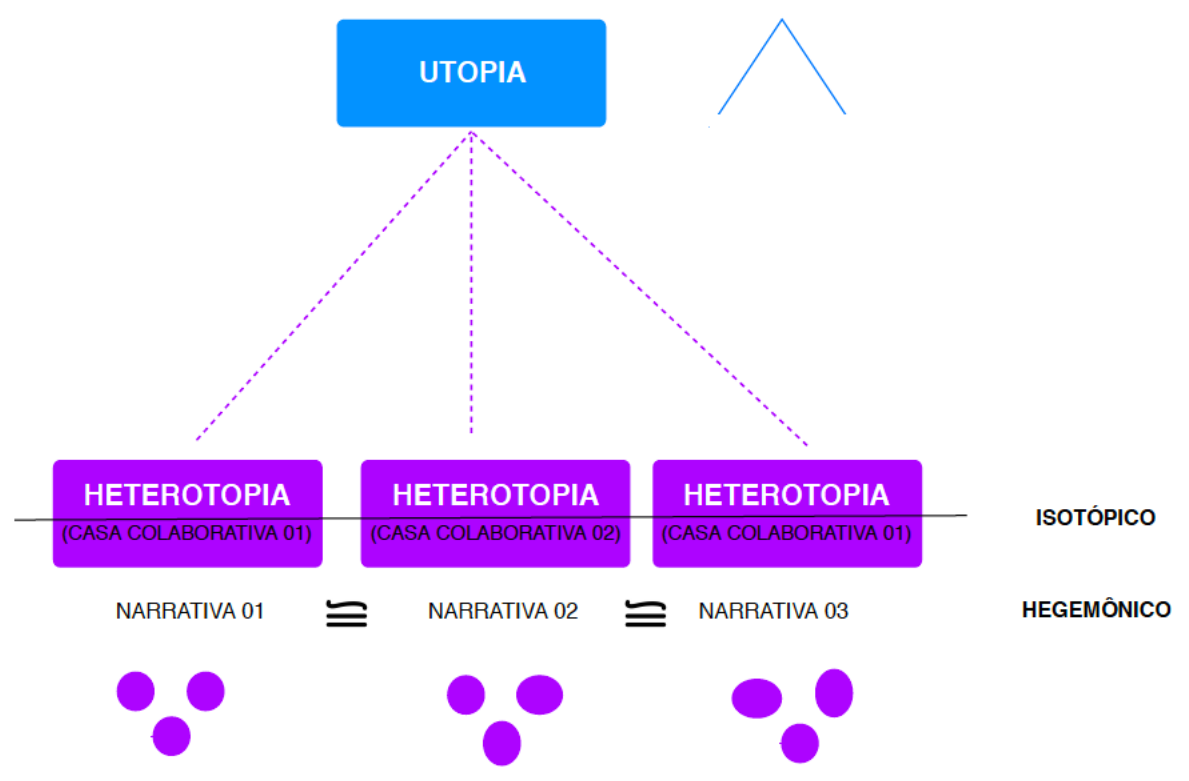

Figura 1: Relação entre utopia, heterotopia e isotopia

As heterotopias poderiam, portanto, ser isotópicas, caso não houvesse hegemonia de uma narrativa sobre outra: seriam distópicas quando, na rede de relações de poder, uma narrativa tivesse predominância sobre as demais. Não haveria disputas plurais e equilibradas entre as heterotopias, o que poderia ser também transformador. Se as utopias são modos de pensar transformadores, são as distopias que remetem a uma realidade diferenciada, porque 
correspondem a uma operação sobre as heterotopias, realidade inovadora, então. O que daí resulta é inaugural, no sentido de que é a não-presença dos fatores marcantes nas utopias e nas heterotopias, e, talvez por isso, esses consigam pautar a crítica pelo que está fora (não marcado) dos sistemas hegemônicos, como apresenta a figura 2. Nesse sentido, a condição para que as Casas Colaborativas respondessem a seus objetivos seria a de serem construções heterotópicas. Enfim, tempo e espaço são duas categorias organizadoras das heterotopias.

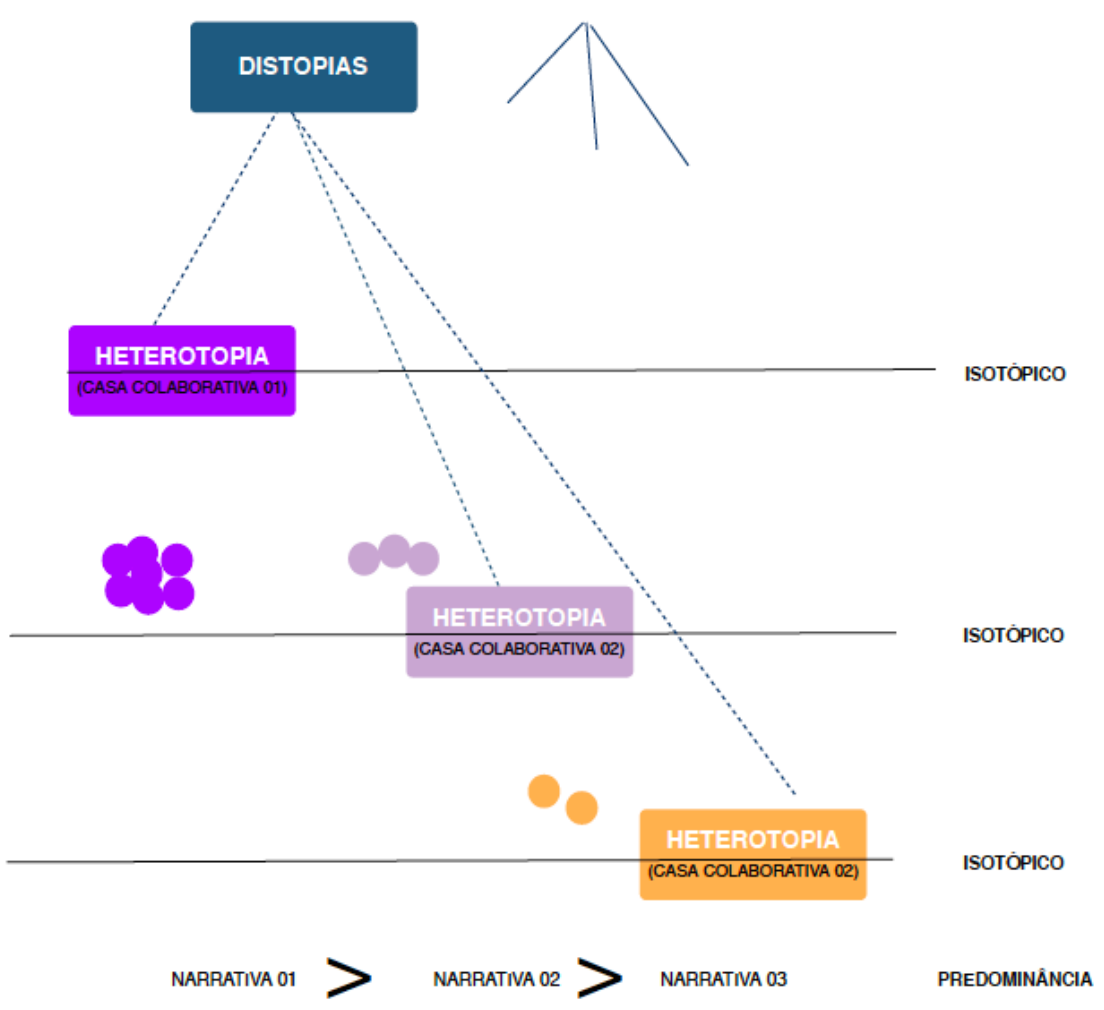

Figura 2: Relação entre distopia, heterotopia e predominância

Os espaços heterotópicos produzem um deslocamento no tempo que se apaga e se sobrepõe, de modo que, nesses espaços, é produzida uma síntese de todas as temporalidades. Seria possível perguntar, então: Quais os agentes da permanência e da mudança? Como se processariam as aberturas e os fechamentos, ou melhor, as subversões e as ratificações? Essas questões apresentam problemas complementares, se considerado que a própria crítica está constrangida pelo fato de que é produzida no contexto dessas mesmas práticas hegemônicas que se quer criticar. Donde, talvez, a relevância das distopias.

\section{Casas Colaborativas}


Dentre as iniciativas de vocação colaborativa e sustentável, estão as Casas Colaborativas, comprometidas com a inovação sociocultural e caracterizadas como lugares de especulação e de experimentação, na perspectiva de design estratégico. São lugares em que a pluralidade de ideias e a diversidade cultural são estimuladoras e (re)criam relações sociais importantes. Aqui, elas são definidas por seus valores e significados, e suas relações expressam-se nas múltiplas atividades que promovem. Elas serão analisadas a partir de processos de design que as orientam e configuram em sua natureza hetero-distópica. Essas Casas, aqui assim designadas, correspondem a espaços para os quais se prevê a ocorrência de atividades diferenciadas nos formatos, mas convergentes em relação às práticas colaborativas sustentáveis que possam inspirar empreendimentos inovadores. Nesse sentido, algumas pesquisas (LITVIN, 2017; MICHELIN, 2017; BUENO, 2018) foram e vêm sendo desenvolvidas e serão objeto de reflexão.

De acordo com Manzini (2008), a criatividade socialmente difusa se expressa no design de atividades que podemos denominar 'colaborativas'. Ele cita, como exemplo, modos de vida em comum nos quais espaços e serviços são compartilhados, como co-housing. Esses espaços, ainda segundo Manzini (2008), são de origem e natureza diversa e se apresentam de diferentes modos. Mesmo assim, possuem um significativo denominador comum, pois são expressão de mudanças na escala local. Essas iniciativas representam descontinuidades/continuidades, ao desafiarem ou confirmarem os modos tradicionais de pensar e fazer. Grupos de trabalho que podem ser definidos como comunidades criativas e que atuam de modo colaborativo inventam, aprimoram e gerenciam soluções inovadoras para novos modos de vida (MERONI, 2007).

Iniciativas deste tipo nascem de problemas ou de desafios fundados na vida real, na vida cotidiana. Assim, são persistentes as ações, e criativas as soluções, no sentido de alcançar, por outros meios, os objetivos sociais. São distopias construídas 'nas e pelas diferenças', as quais quebram modelos dominantes de pensar e fazer, transfiguradas em discursos e práticas não hegemônicas. Nesse sentido, Litvin e Franzato (2017, p. 187) apresentam o movimento das Casas Colaborativas "como os lares das comunidades criativas da cidade, porque recebem uma diversidade de pessoas que articulam projetos orientados para a inovação sociocultural”. Tratase de espaços compartilhados por jovens criativos e empreendedores, inicialmente, para dividir as despesas de aluguel e manutenção em uma lógica de co-working, mas que logo se tornaram promotoras de uma projetualidade fundada na colaboração para a inovação. Segundo os autores, de fato, "os principais traços comuns às casas são o compartilhamento de um espaço de trabalho, a colaboração no desenvolvimento de projetos coletivos e a orientação para a inovação sociocultural" (ibidem, loc. cit.). É importante ressaltar que Michelin, Franzato e Del Gaudio (2017) identificam, nas casas colaborativas, uma possibilidade organizacional que concorre para a construção social alternativa e potencialmente subversiva das hegemonias e do status quo.

Na figura 3, é retratada uma das casas colaborativas da cidade Porto Alegre, o Vila Flores. $\mathrm{Na}$ figura 4, é retratado um projeto hospedado nesta casa, o evento de reflexão crítica sobre a cidade "Sementes Urbanas", organizado pelo SeedingLab, laboratório de design para a inovação 
social e a sustentabilidade, incubado na Universidade do Vale do Rio dos Sinos (UNISINOS) e afiliado à rede de Design of Systems for Social Innovation and Sustainability (DESIS).

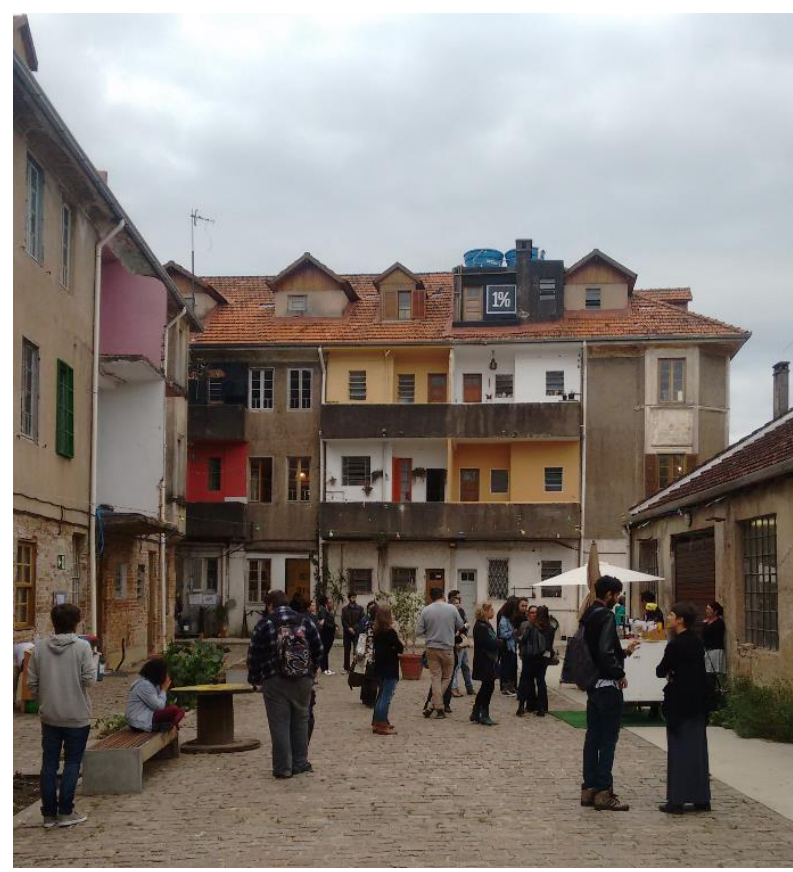

Figura 3: A casa colaborativa "Vila Flores", Porto Alegre/BR²

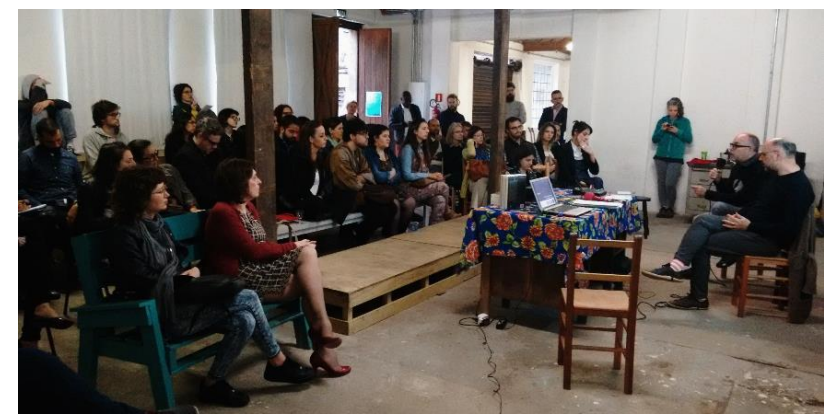

Figura 4: O evento "Sementes Urbanas", organizado pelo SeedingLab no Vila Flores, Porto Alegre/BR

Estudos realizados sobre as Casas Colaborativas de Porto Alegre, Rio Grande do Sul (Brasil), ilustram, com pertinência, as considerações sobre experiências particulares vividas nesses espaços. Litvin (2017) esteve atento ao surgimento de iniciativas na cidade de Porto Alegre, Rio Grande do Sul (Brasil), que agregam pessoas interessadas no desenvolvimento da inovação sociocultural, estimuladas pelo percurso de um projeto colaborativo em rede. Esse tipo

\footnotetext{
${ }^{2}$ Fonte: Disponível em: <http://unisinos.br/seedinglab>. Acesso em: 26/05/2019.

${ }^{3}$ Fonte: Disponível em: <http://unisinos.br/seedinglab>. Acesso em: 26/05/2019.
} 
de colaboração potencializa o compartilhamento de saberes, afecções e linguagens. Este autor apresenta as Casas Colaborativas como laboratórios, e esses, como contexto e como processo, o que lhes confere uma totalidade abrangente de pensamento e de ação.

Se, do ponto de vista dos laboratórios como contexto, já houve avanços, talvez os laboratórios como processos tenham sido um espaço de particular relevância para discutir e formular, coletivamente, critérios de relevância para os sujeitos, para a colaboração e para o ecossistema criativo. É essa a expressão de suas demandas por artefatos que mobilizassem esses atores para as práticas e, por consequência, os empoderassem. Relevante, ainda, o fato de, no contexto de trabalho em que o coletivo é hegemônico, haver lugar para a expressão de sujeitos sobre como representariam as entidades a que estavam ligados, pelo modo como cada um visualiza sua experiência de trabalho colaborativo. Dos esboços sobre os processos colaborativos propostos, destacaram-se os expressos na figura 5 .



Figura 5: Esboços de linguagem

Esse conjunto de formulações correspondem, em diferentes graus e densidades, ao entendimento de "como se colabora para gerar colaboração" (LITVIN, 2017, p. 91) e a que condições os artefatos de colaboração devem responder.

Michelin (2017), por sua vez, aborda processos projetuais com potencial de desenvolver os princípios que pautam as Casas Colaborativas, por ela compreendidas como Seeding. Dessa condição, decorre a possibilidade de sua multiplicação pela formulação de estratégias. A par de competente conceituação, alguns pontos mereceram destaque como marcas identificadoras, conforme está representado na figura 6. 


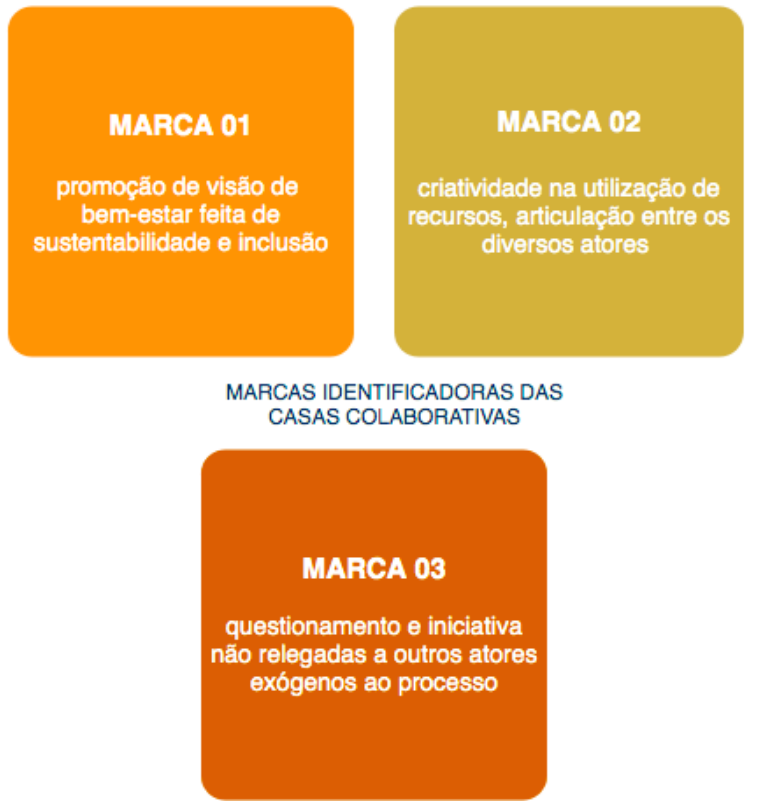

Figura 6: Marcas identificadoras Casas Colaborativas

São essas condições, apresentadas na figura 6, que trazem o reconhecimento das casas colaborativas como espaços de trabalho compartilhado entre atores de diferentes origens e configurações; de produção da inconformidade; de delineamento de propósito(s); de fomento à abertura, à autoralidade e ao vínculo com o(s) território(s); e de relevância do público sobre o privado. Os platôs, assim chamados pela autora, embrionários, territoriais, de consolidação e de evolução, são constructos que favorecem a ação estratégica que contempla, no seu conjunto, a Conceituação, a Organização/Descentralização, a Formação de rede/Confraternização, a Penetração/Recepção e a Difusão, correspondentes, respectivamente, à definição de um propósito, a um modelo organizacional, à formação de núcleos em rede de interação, ao acolhimento e inclusão e às estratégias de comunicação.

Em outra direção de pesquisa, mas também complementar, está o trabalho de pesquisa de Bueno (2018). Ela parte da necessidade de aprofundar a compreensão das potencialidades das Casas Colaborativas como focos de disseminação da inovação social, nos parâmetros da sustentabilidade ambiental, econômica e social, que tem dimensão e modos de atuação, conforme expresso na figura 7. 


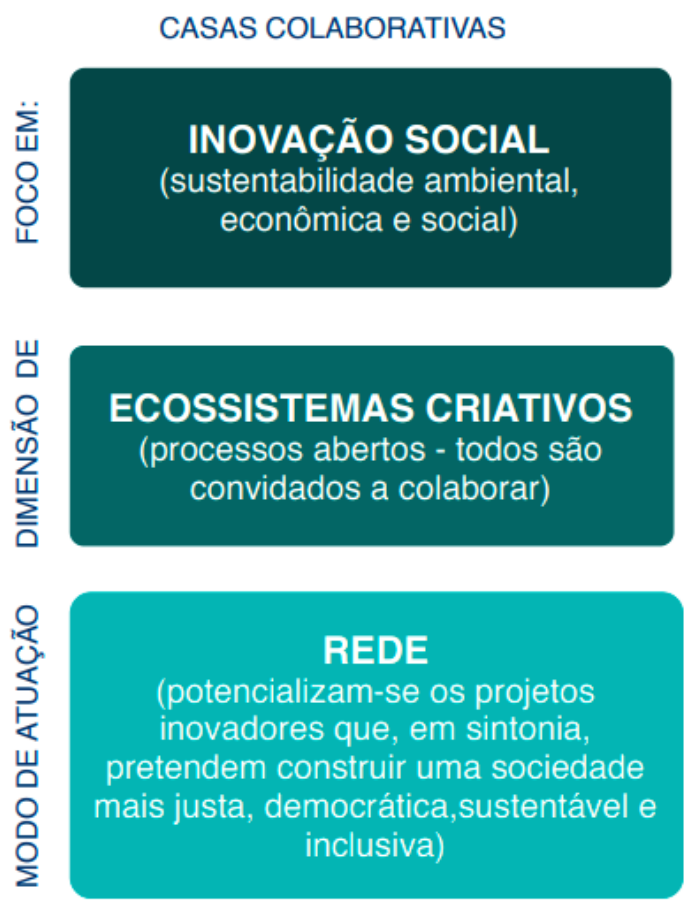

Figura 7: Casas Colaborativas, inovação social e ecossistemas criativos

Particularmente relevantes nos espaços urbanos, essas inciativas reconfiguram recursos, práticas sociais e cenários, na direção do alcance desses objetivos. Sua investigação, suportada pela experiência de criação e atuação em espaços colaborativos, por largo tempo, permite um olhar crítico agudo sobre as configurações, práticas e resultados decorrentes desse esforço coletivo feito pelas Casas Colaborativas, em Porto Alegre. Tal olhar aponta para uma reconfiguração e ressignificação de recursos e práticas sociais cada vez mais comprometidos com a inovação social, e não apenas como espaços em que, colaborativamente, a produzem, mas eles próprios figuram como objetos de inventividade e de atualização.

Sem pretensão de exaustividade, o que se mostra evidente é o vigor que os temas inovação, colaboração e sustentabilidade mantêm, assim como seu potencial de capilaridade para lançar luzes sobre as várias instâncias da sociedade organizada. Em síntese e nos termos expostos, as Casas Colaborativas (ou espaços colaborativos) formam ecossistemas criativos (FRANZATO et al., 2015), ou seja, um tipo de ecossistema cultural caracterizado pelo desenvolvimento de processos criativos que resultam em dispositivos sociotécnicos (artefatos, processos ou sistemas), potencialmente originais e inovadores. Esses ecossistemas estão relacionados aos contextos, às relações e aos fluxos entre os atores dos processos de design. É possível, também, identificar as formações discursivas heterotópicas ou distópicas que os materiais permitem reconhecer, marcadas pelas diferenças, pelos desvios e pelo contraditório. Essas Casas Colaborativas têm suas dinâmicas particulares, e, pelo contrário, não é intenção generalizar suas ações em um conjunto de práticas que sistematize seus processos. 
Como as mudanças são sempre vitais na sociedade humana, a transformação é sempre um devir, algo que ainda não é, mas que está por acontecer, o que potencializa a capacidade de causar surpresa ou espanto. Assim, não existe certeza sobre os efeitos de sentido que serão produzidos pelos dispositivos, até porque, se não por outras razões, também o designer é parte de um sistema vivo de elementos e relações no qual é um entre os diversos atores sociais. As Casas Colaborativas são um exemplo de iniciativas de design que criam espaços diferenciados cujas práticas se caracterizam como heterotopias/distopias, de onde resultam dispositivos, que se materializam em artefatos, produtos e serviços, nas mais diversas formas e linguagens. As Casas Colaborativas, por exemplo, desenvolveriam abordagens que incluíssem relações, posições ou fenômenos que antes seriam descartados como marginais, inconstantes e apolíticos, portanto, indesejáveis. Esses espaços definem-se pelas diferenças não-hegemônicas e, por vezes, surpreendentes. As culturas de design seriam incitadas a operar em heterotopias, que são lugares reais cujas práticas são diferenciadas em relação àquelas normatizadas e previsíveis; seriam, também, incitadas a trabalhar em distopias, espaços-tempo caracterizados pela inversão, suspensão/neutralização da ordem oficial, ou pela nãopresença de cada um desses processos, também tensionados pelas utopias.

\section{Conclusões}

A partir dessas reflexões, abre-se espaço para abordagens metodológicas orientadas pelas utopias/distopias em espaços heterotópicos, como as Casas Colaborativas, aqui objeto de investigação. Com isso, os processos projetuais ganham potência a partir de práticas que surgem desses ecossistemas criativos, modos de pensar e fazer que fogem do convencional. Em síntese, conclui-se que os dispositivos sociotécnicos que resultam desses processos têm a capacidade de alterar o status quo, pois criam novos efeitos de sentido nas sociedades.

A compreensão de isotopia como o princípio ordenador das heterotopias é uma abordagem metaprojetual que pode ser operada metodologicamente nas pesquisas em design a partir dos modelos propostos nas figuras 1 e 2 . Assim, a utopia, enquanto força motriz, orienta os processos em design estratégico não como resultado final, mas como processo projetual, e as distopias marcam o lugar da diferença, portanto, apresentam potencial de inovação. As pesquisas referenciadas de Litvin (2017), Michelin (2017) e Bueno (2018), nas suas particularidades, deslocam o design das margens desses espaços de vanguarda, sonho e criatividade e o aproxima de novos modos de pensar e fazer, nos quais a criatividade e a inventividade colaborativa se destacam. Por isso, essas pesquisas abrem possibilidades de investigação através das Casas Colaborativas como ecossistemas criativos. Importante, ainda, evidenciar que, uma vez parte desses ecossistemas, o design opera e é operado pelos dispositivos que os constituem. E ressalte-se que a relação entre dispositivo, utopia, heterotopia, distopia e isotopia aqui apresentada é profícua para as pesquisas em design que vislumbram as 
transformações sociais, mas que exigem novos esforços de investigação. Em resumo, essas relações podem ser representadas pela figura 8 .

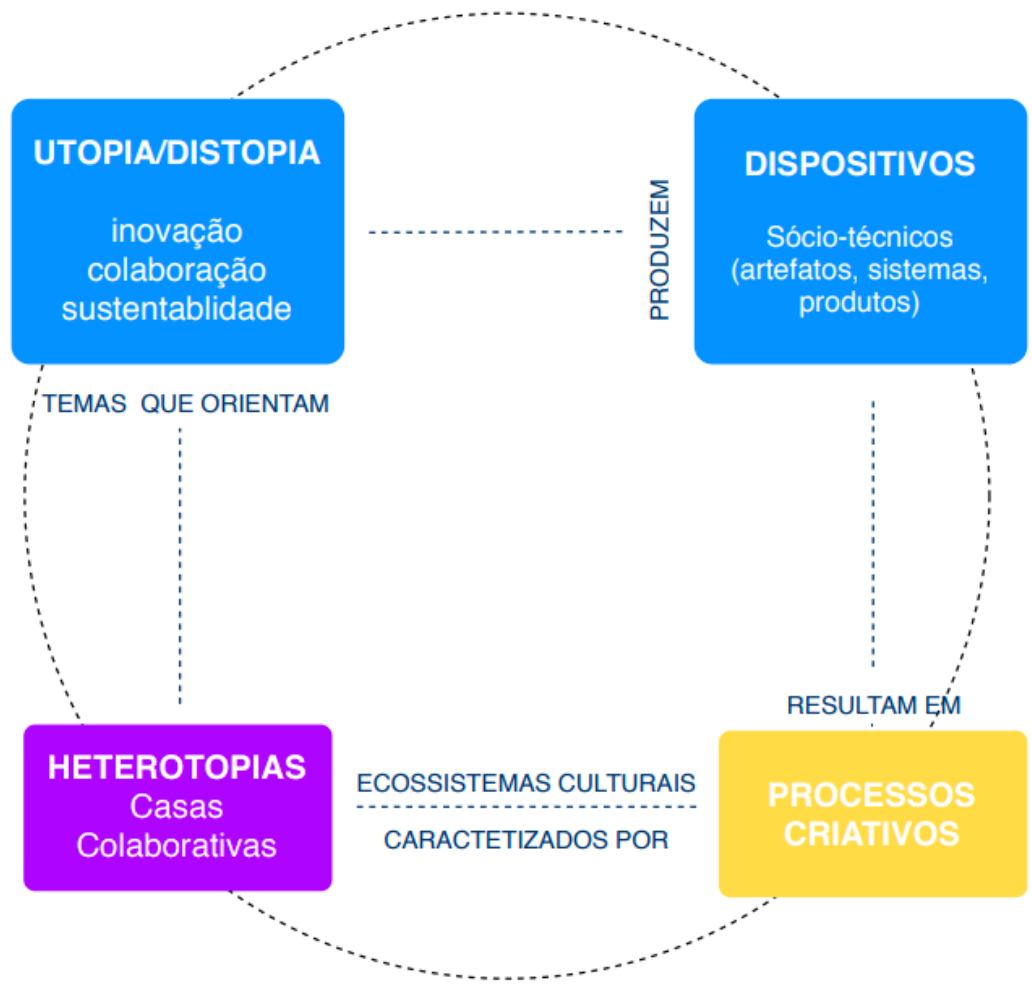

Figura 8: Utopia e Processos Socioculturais

Essa figura evidencia que os dispositivos são resultados de processos criativos, presentes em ecossistemas culturais e que são vivenciados em espaços heterotópicos, como as Casas Colaborativas. Suas práticas colaborativas têm, como força motriz, utopias/distopias presentes em temas como a colaboração e a sustentabilidade que visam à inovação sociocultural. Portanto, não se pretende sistematizar resultados, mas ampliar os caminhos teórico-metodológicos para os estudos que envolvem empreendedorismo, colaboração e inovação sociocultural através das utopias, heterotopias e distopias, por meio de dispositivos.

\section{Agradecimentos}

O presente trabalho foi realizado com apoio da Coordenação de Aperfeiçoamento de Pessoal de Nível Superior - Brasil (CAPES) - Código de Financiamento 001. Carlo Franzato conta com o apoio de bolsa de Produtividade em Pesquisa do Conselho Nacional de Desenvolvimento Científico e Tecnológico (CNPq). 


\section{Referências}

ARGAN, G. C. Projeto e destino. São Paulo: Ática, 2004.

BENTZ, I.; FRANZATO, C. "O metaprojeto nos níveis de design". Blucher Design Proceedings, v. 2, 9, p. 1416-1428, 2016.

BUENO, A. Uma Coalizão de Design para a Transformação Social: propondo diálogos estratégicos entre ecossistemas criativos. Dissertação (Mestrado em Design Estratégico). Programa de Pós-Graduação em Design. Universidade do Vale do Rio dos Sinos: Porto Alegre, 2018. Disponível em: <http://www.repositorio.jesuita.org.br/handle/UNISINOS/7135>. Acesso em: 20.05.2019

DI SALVO, C. Adversarial design. Cambridge: MIT. 2012.

FOUCAULT, M. A ordem do discurso. São Paulo: Loyola, 1970.

As palavras e as coisas. Lisboa: Edições 70, 1991.

Microfísica do poder. São Paulo: Graal, 2004.

FRANZATO, C.; DEL GAUDIO, C.; BENTZ, I.; PARODE, F.; BORBA, G.; FREIRE, K. "Inovação cultural e social: design estratégico e ecossistemas criativos". Em: FREIRE, K. (Ed.). Design Estratégico para a inovação social e cultural. São Paulo: Kazuá, p. 157-181, 2015.

GREIMAS, J. Semântica estrutural. São Paulo: Perspectiva, 1973.

LITVIN, A. K. A Construção Colaborativa de um Processo de Design Estratégico junto com a Rede das Casas Colaborativas de Porto Alegre. Dissertação (Mestrado em Design Estratégico). Programa de Pós-Graduação em Design. Universidade do Vale do Rio dos Sinos: Porto Alegre, 2017. Disponível em: <http://www.repositorio.jesuita.org.br/bitstream/handle/UNISINOS/6638/Aron+Krause+Litv in_.pdf;jsessionid=9539E8291EAEDF7493ACA957A3F70FCC?sequence=1>. Acesso em: 20.05.2019

LITVIN, A. K.; FRANZATIO, C. "Os efeitos do codesign no contexto emergente das Casas Colaborativas". Em: ARRUDA, A. (Ed.). Design \& Inovação Social. São Paulo: Blucher, p. 183-198, 2017. Disponível em: <http://openaccess.blucher.com.br/article-details/10-20520>. Acesso em: 20.05.2019.

MANZINI, E. Design para a inovação social e sustentabilidade | Comunidades criativas, organizações colaborativas e novas redes projetuais. Rio de Janeiro: E-papers, 2008.

MAURI, F. Progettare progettando strategia. Il design del sistema prodotto. Milano: Masson, 1996.

MERONI, A. Creative communities - People inventing sustainable ways of living. Milano: Polidesign, 2007.

Strategic design to take care of the territory - Networking Creative Communities to link people and places in scenario of sustainable development. Anais do $8^{\circ}$ Congresso Brasileiro de Pesquisa e Desenvolvimento em Design, São Paulo, 2008.

MICHELIN, C. Seeding de casa colaborativa na perspectiva do design estratégico. Dissertação (Mestrado em Design Estratégico). Programa de Pós-Graduação em Design. Universidade do Vale do Rio dos Sinos: Porto Alegre, 2017. Disponível em: < http://www.repositorio.jesuita.org.br/handle/UNISINOS/6485>. Acesso em: 20.05.2019. 
MICHELIN, C.; FRANZATO, C.; DEL GAUDIO, C. "Sementes de inovação social como alternativas à hegemonia". Em: ARRUDA, A. (Ed.). Design \& Inovação Social. São Paulo: Blucher, p. 33-50, 2017. Disponível em: <http://openaccess.blucher.com.br/articledetails/02-20512>. Acesso em: 20.05.2019.

MULGAN, G.; TUCKER, S.; ALI, R.; SANDERS, B. Social innovation: What it is, why it matters and how can be accelerated. Oxford: Oxford Said Business School, 2007.

MURRAY, R.; CAULIER-GRICE, J.; MULGAN, G. The open book of social innovation. London: Young Foundation/NESTA, 2010.

ZURLO, F. 2010. "Design Estrategico”. Em: XXI Secolo, vol IV, Gli spazi e le arti. Roma: Enciclopédia Treccani, 2010.

\section{Sobre os autores}

Claudia Palma da Silva é Doutoranda em Design pela UNISINOS, bolsita do PROSUC/CAPES e integrante do GPDEICS Grupo de pesquisa design estratégico: inovação cultural e social. Mestre em Comunicação Social pela PUC-RS. Bacharel em Comunicação Social pela UFRGS. Sócia-diretora da agência de conteúdo digital Browse. Pesquisa temas relacionados ao processos criativos em Design, projetação por cenários e narrativas imagéticas.

claudiapalmadasilva@gmail.com

Ione Maria Ghislene Bentz, doutora em Linguística e Semiótica pela USP, Estágio Pós-doutoral Paris -Sorbonne, professora, pesquisadora e orientadora no Programa de Design - Mestrado e Doutorado na UNISINOS, desenvolve pesquisa em Crítica às teorias de design e em Processos de Significação e Comunicação em projetos de design. Atua na condução de seminários de estudos avançados e na liderança de Grupos de Pesquisa.

ioneb@unisinos.br

Carlo Franzato é designer e doutor em Design pelo Politecnico di Milano. É professor de Design Estratégico na UNISINOS. Na perspectiva da complexidade e no escopo metodológico do design estratégico, sua pesquisa tem como tema central as redes de projeto que se constituem com a abertura do processo de design para a pluridiversidade das relações colaborativas entre os atores dos ecossistemas criativos.

cfranzato@unisinos.br 